\title{
Organochlorine compound levels in fertile and infertile women from Rio de Janeiro, Brazil
}

\author{
Níveis de substâncias organocloradas em mulheres \\ férteis e inférteis do Rio de Janeiro, Brasil
}

Ana Marcia Xavier Bastos', Maria do Carmo Borges de Souza $^{2}$, Gutemberg Leão de Almeida Filho², Thomas Manfred Krauss $^{3}$, Thelma Pavesi ${ }^{3}$, Licínio Esmeraldo da Silva'

\footnotetext{
1 Universidade Federal Fluminense (UFF), Niterói, RJ, Brazil 2 Universidade Federal do Rio de Janeiro (UFRJ), Instituto de Ginecologia, Rio de Janeiro, RJ, Brazil ${ }^{3}$ Centro de Estudos da Saúde do Trabalhador e Ecologia (CESTEH) Escola Nacional de Saúde Pública Sérgio Arouca (ESNP), Fundação Oswaldo Cruz (Fiocruz), Rio de Janeiro, RJ, Brazil

This study was developed at the Universidade Federal do Rio de Janeiro
}

\begin{abstract}
Objective: The aim of the study was quantify organochlorine compounds in women seeking for infertility treatment $(n=15)$ and in spontaneously pregnant ones $(n=21)$. Materials and methods: A questionnaire was applied regarding lifestyle, occupational and reproductive history. Blood samples were collected from both groups. Results: From the pesticides studied, pp'DDE was detected in $100 \%$ of infertile women, at higher mean levels than in pregnant women (3.02 $\mathrm{mcg} / \mathrm{L} \mathrm{vs.} 0.88 \mathrm{mcg} / \mathrm{L} ; \mathrm{p}=0.001$; power of $69 \%$ ), without correlation with the etiology of infertility. Levels of the polychlorinated biphenyls (PCBs) were low, with positive samples in $100 \%$ in the infertile women for PCBs $138,153,180$, while in pregnant women, they were $85.7 \%$ for congeners 138 and 153. Only PCB180 showed significance, with frequency of $71.4 \%$ ( $p=0.019)$. Conclusions: The risk factors for female infertility were: age, consumption of untreated water and of canned foods. Exposure to the most prevalent organochlorine compounds described in literature was confirmed in the study, indicating that $\mathrm{pp}^{\prime} \mathrm{DDE}$ may adversely influence female fertility. Arq Bras Endocrinol Metab. 2013;57(5):346-53
\end{abstract}

Keywords

Organochlorine pesticides; polychlorinated biphenyls; female fertility; endocrine disruptors

\section{RESUMO}

Objetivo: O estudo teve como objetivo quantificar as substâncias organocloradas em mulheres buscando tratamento para infertilidade $(n=15)$ e que espontaneamente engravidaram $(n=21)$. Materiais e métodos: Foi aplicado questionário considerando estilo de vida, história ocupacional e reprodutiva. Amostras de sangue foram obtidas em ambos os grupos. Resultados: Dos pesticidas, $\mathrm{pp}$ 'DDE foi detectado em $100 \%$ das inférteis, com níveis maiores que nas grávidas (3,02 mcg/L vs. 0,88 mcg/L; $p=0,001 ;$ poder 69\%), sem correlação na etiologia da infertilidade. Os níveis de detecção das bifenilas policloradas (PCBs) foram baixos, com 100\% de positividade das amostras nas inférteis para os PCBs 138, 153, 180, e de 85,7\% nas grávidas para os congêneres 138 e 153. Apenas PCB180 mostrou significância na frequência de 71,4\% ( $p=0,019)$. Conclusões: Os fatores de risco para infertilidade feminina foram: idade, consumo de água não tratada e alimentos enlatados. A exposição aos organoclorados mais prevalentes descritos na literatura foi confirmada no estudo, indicando que $p^{\prime}$ 'DDE pode influenciar adversamente a fertilidade feminina. Arq Bras Endocrinol Metab. 2013;57(5):346-53

Descritores

Pesticidas organoclorados; bifenilas policloradas; fertilidade feminina; desreguladores endócrinos 


\section{INTRODUCTION}

$\mathrm{T}$ he second half of the $20^{\text {th }}$ century witnessed an increase in population growth that has been accompanied by a decline in fertility rate (1), especially in developed countries. Social, economic, and cultural factors, such as better quality of life and, consequently, higher survival rates, may explain the present overpopulation. In contrast, women entry into the job market, postponing maternity, as well as the availability of effective contraception methods may explain the low fecundity rate in the modern world (2).

The Brazilian Census, published by the Brazilian Institute of Geography and Statistics, showed that the fecundity rate in Brazilian women decreased from 2.54 to 1.95 children per woman, on average, between 1997 and 2007, and the proportion of childless couples increased from $12.9 \%$ to $16 \%$ during the same period $(3,4)$.

With the advent of the industrial era, environmental pollution began to harm wildlife and human health; however, most of the studies have focused mainly on the mutagenic, teratogenic, and carcinogenic manifestations of environmental pollution. In general, the scientific community supports the idea that pollution is causing a negative impact on health, but very little is known about its impact on reproductive capacity. Several epidemiologic studies have observed deleterious effects of chemical agents following chronic exposure $(5,6)$ in accidentally contaminated sites $(7-11)$.

Numerous synthetic and natural environmental compounds known as endocrine disruptors (EDs) are found to modulate and alter endocrine functions, effectively mimicking or blocking those functions, e.g., by means of estrogenic, anti-estrogenic, and/or antiandrogenic effects. They have potential to act as endogenous hormones by binding to steroid hormone receptors. Among these compounds, organochlorines are a class of persistent bioaccumulative chemicals considered priority pollutants, which enter the food chain, and are also found in remote areas (12). About twelve toxic organic substances considered persistent organic pollutants (POPs) had their production and release in the environment reduced after the Stockholm Convention of the United Nations Environment Programme (13).

Among persistent chemicals are pesticides used in agriculture (DDT), which fight organisms that are harmful to men, such as disease-transmitting vectors or crop pests; despite the prohibition of large-scale use, they are still used in endemic areas, e.g., against malaria mosquitoes in Brazil (14). Polychlorinated biphenyls (PCBs) are considered environmental pollutants, but are used in a variety of industrial applications, such as organic solvents, plastics, sealants, and adhesives on heat transfer fluids for transformers and capacitors (15). Chemical products are also used in cosmetics, anabolic steroids for animal feeding, phytoestrogens in the diet, and are seen in residential, industrial, and urban sewerage system effluents, representing an important source of environmental contamination (16).

Exposure to these compounds during the developmental period causes reproductive abnormalities in adult life, and it has been suggested that they are transgenerational. As female reproductive function depends upon ovarian steroidogenesis that enables folliculogenesis, ovulation, and pregnancy, the impact of altering ovarian development and function in female fertility may be the link between environmental exposure and reproductive failure (17).

Establishing risk factors for the general population is difficult and occasionally questioned by some authors, as exposure, either at work or at home, cannot be easily characterized, and hence, cannot be proven. A number of adverse effects have been described in the literature, such as higher number of abnormalities in male genitalia, variation in birth sex rate, reduction in the quantity and quality of sperm, lower rate of fertility and fertilization, and higher rate of miscarriage and time to achieve pregnancy (18).

During the last decade, several clinical studies have attempted to validate the hypothesis that adverse effects on human health owing to environmental exposure, including reproductive capacity, are often caused by endocrine disruption (19). Time to Pregnancy (TTP) is a tool for the retrospective study of fecundability (20). Evidence associating exposure to TTP increase deserve special attention and, as some geographic regions are more contaminated than others, differences should be analyzed in each specific population (21). Berman and cols. (22), reviewed studies regarding trends in reproductive health in Israeli population and found a decrease in the age of menarche from 1986 to 2000 and in the prevalence of male factor infertility. The authors supported the idea that endocrine-disrupting chemicals must be regulated and public exposure reduced, especially in sensitive groups such as children and pregnant women. Ozen and cols. (23), evaluated the ef- 
fects of pesticides on the development of precocious puberty in girls living in an agricultural region and, with exception of DDE, the pesticides studied were undetectable in serum and adipose tissue. Toshiba and cols. (24), analyzed chemicals in urine of 42 Japanese male partners of subfertile couples and suggested that pyrethroid exposing level and dietary habits (coffee and soy products) as significant contributors to poorer semen quality.

In a systematic review (25) evaluating evidence of an association between EDs exposure and women reproductive health, articles published until 2010 were not always consistent, in part due to limitations imposed by practical constraints. Reviewers recommended the development of appropriate biomarkers in order to make progress in this field.

Taking into consideration the diversity of clinical situations involved, the plausible association between environmental exposure and altered reproductive function is difficult to prove. The aim of the present study was to quantify organochlorine pesticides and polychlorinated biphenyls, the most prevalent compounds described in the literature, in the serum of fertile and infertile women living in two urban areas of the state of Rio de Janeiro.

\section{MATERIALS AND METHODS}

The study and the related protocols were approved by the Ethics Committee for Research of the University Hospital of Universidade Federal do Rio de Janeiro. All participants signed an informed consent form.

\section{The sample}

The groups comprised women at reproductive age, between 18 and 38 years, that spontaneously achieved pregnancy in a period no longer than 12 months (fertile group), and those seeking specialized treatment for infertility as they did not become pregnant in one year of unprotected sexual activity (infertile group). The following exclusion criteria for the latter group were: medical treatment in the previous 3 months, premature ovarian failure, male factor (oligoastenospermy or azoospermy) or surgical sterilization (tubal ligation or vasectomy). The fertile group was constituted of women randomly chosen at prenatal appointments, after twelve weeks of gestational age, as miscarriage was considered reproductive failure. The exclusion criteria in this group were to be nursing or to have weaned the child less than 12 months before the study; to be under medication or to have systemic disease; or women whose partners presented history of subfertility.

\section{Data collection}

A translated version of the Greenlee and cols. (6) questionnaire was provided to both groups, between March and December 2006, taking into consideration the participants lifestyle, and occupational and reproductive history for epidemiological characterization and possible exposure to risk factors.

\section{Analysis of organochlorine compounds}

Samples were collected along with routine hormonal dosages during infertility investigation, as well as prenatal laboratory tests in the control group. Blood samples were drawn from the forearm vein and collected in a Vacutainer ${ }^{\circledR}$ silicone tube without an anticlotting agent. After spontaneous coagulation, serum was separated by centrifugation. Around $5 \mathrm{~mL}$ of the serum were kept frozen at $-30^{\circ} \mathrm{C}$ for the subsequent analysis of organochlorine compounds.

The following substances were analyzed in the serum samples: hexachlorobenzene (HCB); dichlorodiphenyl-trichloroethane (DDT, pp' and op'isomers), dichlorodiphenyl-dichloroethane (DDD, pp' and op' isomers), dichlorodiphenyl-dichloroethylene (DDE, pp' and op' isomers), and six marker PCBs ( $\mathrm{N}^{\circ} 28$, $52,101,138,153$, and 180). Instrumental analyses were conducted on Agilent $6890 \mathrm{~N}$ gas chromatograph equipped with an Agilent $5973 \mathrm{~N}$ mass selective detector, operated in the selected ion monitoring mode. Quantification thresholds varied from 0.01 to $0.02 \mathrm{ng} /$ $\mathrm{mL}(=\mathrm{mcg} / \mathrm{L})$ for the PCBs, and from 0.03 to 0.05 $\mathrm{ng} / \mathrm{mL}(=\mathrm{mcg} / \mathrm{L})$ for the DDT group and HCB. Recovery varied from 83 to $105 \%$ for the PCBs, and from 79 to $94 \%$ for the organochlorine pesticides.

\section{Statistical analysis}

Statistical data description was carried out using different parameters (absolute frequency, proportion, average, standard deviation, minimum and maximum values, median, and interquartile deviation), tables, and graphs (box plots). Comparisons between the proportion of independent samples were carried out with the $\chi^{2}$ test. 
Correlations among normal continuous variables were studied by means of Pearson's correlation coefficient, and correlation among variables that did not show normal distribution were analyzed by means of Spearman's correlation coefficient. The Shapiro-Wilk test checked normal data. Comparisons of two different groups with independent data without normal distribution were carried out using Mann-Whitney test. The level of significance was $\alpha=0.05$ (where $p \leq 0.05$ was significant). Power analysis was carried out after the significance test, using the observed difference to the null hypothesis as the effect size.

Statistical analysis was conducted using Microsoft Excel and SPSS statistical package version 10.0 from SPSS Inc.

\section{RESULTS}

From the 27 subjects who answered the questionnaire in each group, 21 pregnant and 15 infertile women completed blood sampling. No differences were found between the groups in relation to alcohol consumption, smoking, passive smoking, and body mass index, or in variables related to menstrual history (age of menarche, sexual initiation, and menstrual cycles.

Both groups had the same social, demographic, and economic characteristics, and only differed in age. Median age of infertile patients was 30.9 years (S.D. \pm 4.5 ), whereas it was 25.7 years in the fertile group (S.D. \pm 5.4 ), demonstrating significant difference (Student's $\mathrm{t}$ test: $\mathrm{t}=$ $2.996 ; \mathrm{df}=34 ; \mathrm{p}$-value $=0.005)$. In the infertile group, $40 \%$ of the patients were between 31 and 35 years of age, whereas in the pregnant group, this age range represented only $4.8 \%$ the sample (Chi-square test: $\chi^{2}=6.937$; $\mathrm{df}$ $=1 ; \mathrm{p}$-value $=0.008)$. These data are presented in table 1 .

Table 1. Comparison of the proportion of fertile and infertile women by age intervals

\begin{tabular}{lcccccc}
\hline & \multicolumn{5}{c}{ Groups } \\
\cline { 2 - 3 } Age (years) & \multicolumn{2}{c}{ Fertile } & & \multicolumn{2}{c}{ Infertile } & p-value \\
\cline { 2 - 3 } & $\mathbf{n}$ & $\%$ & & $\mathbf{n}$ & $\%$ & \\
\hline$\leq 20$ & 4 & 19.0 & & - & 0.0 & ns \\
$21---25$ & 6 & 28.6 & & 3 & 20.0 & ns \\
$26---30$ & 8 & 38.1 & & 4 & 26.7 & ns \\
$31--35$ & 1 & 4.8 & & 6 & 40.0 & $0.008^{\star}$ \\
$>35$ & 2 & 9.5 & & 2 & 13.3 & ns \\
Total & 21 & 100 & & 15 & 100 & - \\
\hline
\end{tabular}

ns: no statistical significance $(p>0.05)$.

*: statistical significance $(p<0.05)$
Gestational age ranged from 14 to 36 weeks, with a median of 23.8 weeks of pregnancy; $57.2 \%$ of the control group was in the second trimester, and $42.8 \%$ in the third trimester of pregnancy. Among the 21 pregnant women, $9(42.8 \%)$ were in their first pregnancy, and $12(57.2 \%)$ had conceived before.

All the women lived in a metropolitan area with appropriate water and sewage systems. However, ingestion of tap water was significantly different between the groups (Chi-square test: $\chi^{2}=4.573 ; \mathrm{df}=1 ; \mathrm{p}$-value $=$ 0.032 ), with $46.7 \%$ of the infertile patients, and $14.3 \%$ of the fertile ones consuming tap water. The other options were: use of well water (only one infertile $v s$. three pregnant women), filtered tap water and mineral water, without significance in these variables. There was no significance in the consumption of meat or dairy products, either. On the other hand, there was significant difference (Chi-square test: $\chi^{2}=5.783$; $\mathrm{df}=1$; $\mathrm{p}$-value $=0.016)$ in the consumption of canned foods once a week $(86.7 \%$ case $v$ s. $47.6 \%$ control). Exposure to pesticides, such as insecticides, in the previous two years was similar in both the groups $(73.3 \%$ for infertile vs. $81 \%$ for fertile women), but the use of repellents was reported by $20 \%$ of infertile patients against $0 \%$ of pregnant woman (Chi-square test: $\chi^{2}=4.582 ; \mathrm{df}=1$; $\mathrm{p}$-value $=0.032)$.

Regarding the DDT group, op'DDD and op'DDE isomers were not present in any of the analyzed samples, while op'DDT was observed in $13.3 \%$ patients in the experimental group and none in the control group. Among polychlorinated biphenyls, PCB 28 was negative in all samples, while PCB 52 was positive once in each group. Congener 101 was present in $33.3 \%$ of the infertile patients and in $28.5 \%$ of the controls, but it did not show any statistical difference.

Table 2 shows the levels of the most prevalent organochlorine compounds (minimum, maximum, mean, and standard deviation) in both the groups. In the serum samples from both infertile and fertile patients, detectable levels of four kinds of organochlorine pesticides were found: HCB, pp'DDT, pp'DDD, and pp'DDE. The fungicide HCB was detected in seven samples from each group, with a mean of $0.21 \mathrm{mcg} / \mathrm{L}$ vs. $0.09 \mathrm{mcg} / \mathrm{L}$, for infertile and fertile patients, respectively, without any statistical significance. Samples were positive for pp'DDT in 5 out of 21 cases in the control group (23.8\%), and 2 out of 15 patients in the experimental group (9.5\%); pp'DDD was positive in only two patients of each group. It is worthy emphasi- 
Table 2. Statistical description of organochlorine compound levels in fertile and infertile groups

\begin{tabular}{|c|c|c|c|c|c|c|c|c|c|c|c|}
\hline \multirow{2}{*}{ Organochlorines } & & \multicolumn{5}{|c|}{ Fertile $(n=21)$} & \multicolumn{5}{|c|}{ Infertile $(n=15)$} \\
\hline & & $\mathbf{n}$ & $\min$ & $\max$ & mean & sd & $n$ & $\min$ & $\max$ & mean & sd \\
\hline \multirow[t]{3}{*}{ Pesticides } & $\mathrm{HCB}$ & 7 & 0.04 & 0.31 & 0.09 & 0.10 & 7 & 0.04 & 1.04 & 0.20 & 0.37 \\
\hline & pp'DDE & 20 & 0.12 & 3.32 & 0.88 & 0.81 & 15 & 0.40 & 11.56 & 3.02 & 3.57 \\
\hline & pp'DDT & 5 & 0.50 & 0.86 & 0.66 & 0.14 & 2 & 0.74 & 11.50 & 9.12 & 11.88 \\
\hline \multirow[t]{3}{*}{ PCBs } & 138 & 18 & 0.01 & 0.34 & 0.06 & 0.08 & 15 & 0.02 & 0.26 & 0.07 & 0.07 \\
\hline & 153 & 18 & 0.02 & 0.19 & 0.07 & 0.06 & 15 & 0.02 & 0.16 & 0.07 & 0.05 \\
\hline & 180 & 15 & 0.01 & 0.21 & 0.07 & 0.05 & 15 & 0.02 & 0.21 & 0.08 & 0.06 \\
\hline
\end{tabular}

n: absolute frequency; min: minimum value; max: maximum value; mean: arithmetic mean; sd: standard deviation. All parameters values (except $n$ ) are expressed in mcg/L. HCB: hexachlorobenzene; pp'DDE: dichlorodiphenildichloroetilene; pp'DDT: dichlorodipheniltrichloetane; PCBs: polychlorinated biphenyls.

zing that the main metabolite of DDT, pp'DDE, was the only isomer found in $100 \%$ of the infertile patients and in $95.3 \%$ of the pregnant women (except for one fertile woman who had undetectable levels). The levels in infertile women were higher than those detected in the control, with a significant difference between the groups (Mann-Whitney test: $\mathrm{U}=56$; p-value $=0.001$; power of $69 \%$; Figure 1). Reviewing the analysis in three separate age groups for fertile and infertile women, pp' DDE levels varied from $0-3-32 \mathrm{mcg} / \mathrm{L}$ and $0.40-4.43 \mathrm{mcg} / \mathrm{L}$, respectively, in fertile and infertile women, between 21 and 30 years old, without statistical difference. On the other hand, the subgroup over 30 years old showed difference between the groups (Mann-Whitney test: $\mathrm{U}=0$; $\mathrm{p}$ - value $=0,012$; Figure $2)$. The variation in this age group was $0.28-0.82$ $\mathrm{mcg} / \mathrm{L}$ for fertile women and $0.87-11.56 \mathrm{mcg} / \mathrm{L}$ for infertile ones.

Polychlorinated biphenyls were detected only at low levels. However, the frequency of positive samples for congeners 138,153 , and 180 was $100 \%$ in infertile pa-

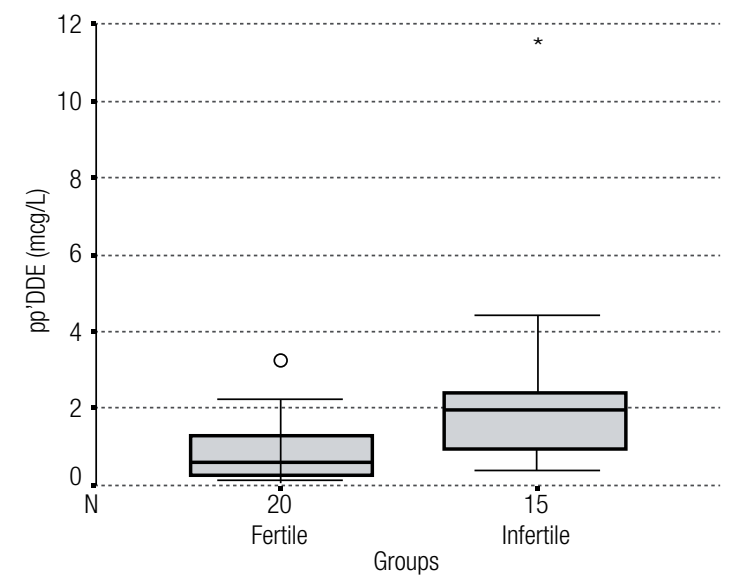

pp'DDE: dichlorodiphenildichloroetilene; mcg/L: microgram/liter. * Maximun value (11.56 mcg) for pp'DDE in the infertile group ( $p=0.001$; power $69 \%$ ).

Figure 1. Box plots of pp'DDE levels observed in fertile and infertile groups. tients. Congeners 138 and 153 were detected in $85.7 \%$, and PCB 180 in $71.4 \%$ of the patients in the control group; however, only PCB 180 frequency showed significant difference between the groups (Chi-square test: $\chi^{2}=5.456 ; \mathrm{df}=1 ; \mathrm{p}$-value $=0.019 ;$ Figure 3$)$. There was no significant difference in the levels of pp'DDE, PCB 138, PCB 153, and PCB 180 in the samples of the control group, when subgroups were compared, that is, when women in the first pregnancy were compared with those who had achieved pregnancy before.

Etiologic diagnoses in infertile women were: $33.3 \%$ tubal factor (uni- or bilateral obstruction), 20\% ovulatory dysfunction (anovulation), and 20\% both tubal and ovarian factors. There were two cases of uterine factors (uterine septum and unicornus), and in other two cases, the cause of infertility could not be found, and they were classified as idiopathic. No cases of endometriosis were found. There were no features or clinical suspicion of polycystic ovarian syndrome (PCOS), and hormonal assays excluded the possible involvement of hyperprolactinemia and hypothyroidism.

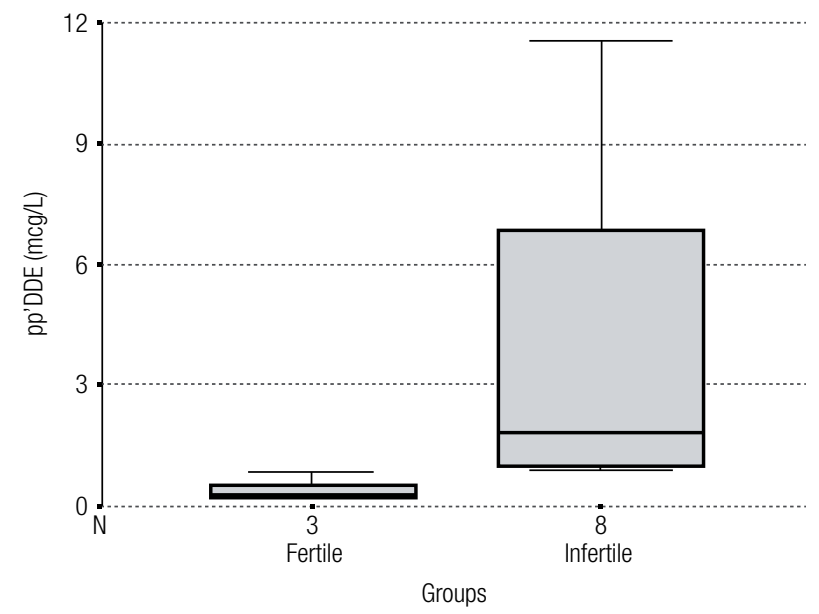

pp'DDE: dichlorodiphenildichloroetilene; mcg/L: microgram/liter.

Figure 2. Box plots of DDE's levels of women above 30 years old in fertile and infertile groups. 


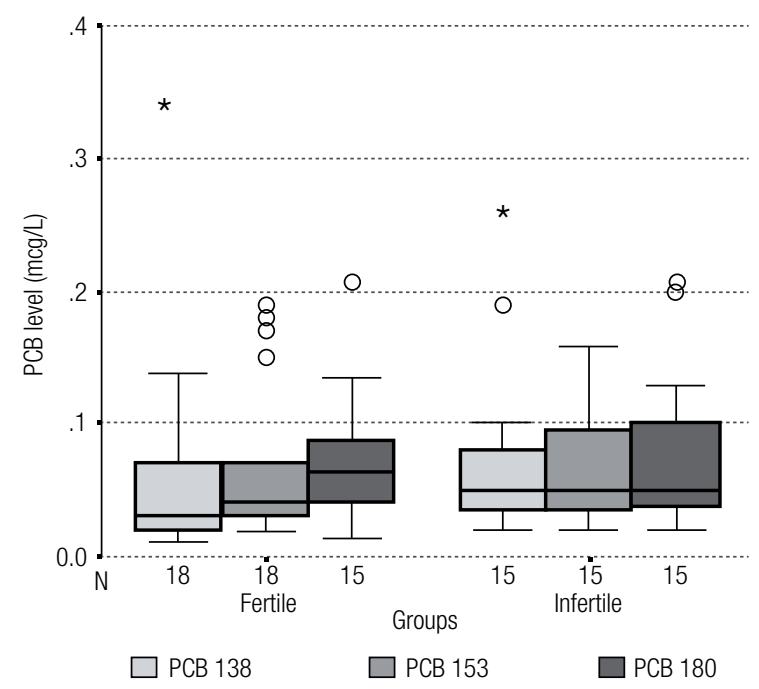

PCBs: polychlorinated biphenyls; mcg/L: microgram/liter. * Maximum values for PCB 138 in the fertile $(0.34 \mathrm{mcg})$ and infertile $(0.26 \mathrm{mcg})$ patients.

Figure 3. Box plots of PCBs levels in fertile and infertile groups.

\section{DISCUSSION}

Infertility is defined as the incapacity to achieve pregnancy after one year of regular unprotected intercourse. The authors considered a major health problem in both developed and developing countries, affecting $10 \%$ of the population (2). This is the first study involving an urban population, comparing organochlorine compounds in the serum of infertile and fertile women from the same area of Rio de Janeiro. Most of the published trials analyzed TTP retrospectively, as an epidemiological tool representing fecundity in exposed populations, such as in agricultural areas. On the other hand, samples consisted of women considered fertile, excluding the infertile ones, who did not achieve spontaneous pregnancy.

Greenlee and cols. (6) translated questionnaire was chosen as the instrument to evaluate exposure to risk factors, because it is the one that best approaches the study of female infertility considering the etiology and the possible variables involved. Although Greenlee's study was in agricultural population and the present research was conducted with women living in an urban area, the questionnaire was useful. Demographic data, and information related to menstrual and reproductive history, as well as lifestyle proved to be of great value for the epidemiological characterization of the sample. A shorter and more objective questionnaire would contribute to future studies on environmental issues affecting human reproduction.
Age is a determinant factor in fertility because ovarian reserve is reduced as women get older. In the present study, mean age of infertile patients was significantly higher than of the fertile ones, but the average time of infertility in the experimental group was 52.4 months (varying from 1 to 12 years). When analyzing the sample with respect to age and time to pregnancy, infertile women were older and showed significant difference in TTP when compared with fertile ones, specifically in the subgroup over 31 years old. Also, in a case-control study, Smith and cols. (21) found the duration of infertility lasting from 1 to 19 years, and similar mean value of 4 years. Both studies showed the long evolution of the disease and the difficulty in solving the cases, stating that age could be a risk factor for infertility.

In contrast, Greenlee and cols. (6) found similar mean age in the fertile and infertile groups $(29.7 \mathrm{vs}$. 29.9 years) showing no interference of age in female fertility. Age may also influence organochlorine levels due to the longer period of exposure and, consequently, greater accumulation of these compounds. In the present study, the highest pp'DDE levels were found in two infertile women, aged 36 and 37 years, which emphasize the persistence in older people. The difference between pp'DDE levels found in the subgroup of infertile women over 30 years old may explain a negative impact in women fertility.

Another factor to be considered is the time of birth of the sample studied. These women were born between 1969 and 1988, when these chemicals had not yet been banned in Brazil; therefore, the in utero exposure could have been possible. Although the questionnaire did not evaluate living conditions, work, and lifestyle of patients' parents, there was no report of residences in rural, agricultural and/or cattle-raising areas, or of the use of pesticides in childhood and adolescence in any of the groups.

There was a significant difference in the intake of drinking water between the groups, with the infertile patients consuming tap water more frequently than the fertile ones. Greenlee and cols. (6) showed that the supply of private well water could present lower risk to infertility than water from the public water supply systems, which is considered to have higher concentration of chemical substances added for treatment. However, in 2004, Silva (26) reported the absence of HCB, DDT and its metabolites in the water supplied by the city of Rio de Janeiro.

According to the World Health Organization, the population is primarily exposed to PCBs by means of 
ingestion of fish and other products of animal origin, such as meat, poultry, milk, cheese, and eggs (27). However, no conclusion about the differences in exposure to organochlorines by food intake was visible, because only one infertile woman reported consumption of fish, and in both the studied groups, food consumption was exclusively based on chicken and beef in similar proportions. Sarcinelli and cols. (28) investigated organochlorine levels in the plasma and umbilical cord blood of women and their newborns living in Rio de Janeiro. Out of the predictive variables analyzed (body mass index, menarche, maternal and gestational ages, parity, and eating habits), pp'DDE was the only chemical that showed significance, presenting a positive correlation with the consumption of fish and chicken.

In pregnant women, blood samples were collected in the second or third trimester of pregnancy in similar proportions. Some factors may interfere with the levels of environmental chemical substances, such as body weight changes during pregnancy, as well as metabolism and energy intake, but according to Longnecker and cols. (29), the moment of serum sampling is not critical with regard to the organochlorine concentrations. In the present study, the authors found that the levels were greater than or equal to the detection threshold in all the samples of pregnant patients, for both DDE and PCBs, although DDE levels were higher than usually reported in the literature compared with PCBs level, which were similar. Although the limits of detection in the studied samples were low, PCBs 138, 153, and 180 were $100 \%$ positive in all the infertile patients, and pp'DDE levels were higher in the experimental group, confirming the data in literature. According to Safe and Hoivik (30), these are the most common organochlorine compounds found in humans. In addition, these compounds were also identified in the control group, but in lesser amounts, indicating that both the groups are exposed.

The influence of breastfeeding on organochlorine levels was also excluded, because the levels of the four most frequent compounds (pp'DDE, PCB 138, PCB 153 , and $\mathrm{PCB} 180$ ) were not altered when compared with the two subgroups of pregnant women. Almost half of the women were pregnant for the first time, and hence, had never breastfed before, and those who had at least one child alive, had already weaned them for over 12 months. In contrast, Sarcinelli and cols. (28) reported significant higher pp'DDE plasma levels in nulliparous women than in the multiparous ones; however, they did not provide any information regarding breastfeeding.
Younglai and cols. (31) studied the association between fertilization failure in 21 couples undergoing IVF and exposure of both partners to environmental contaminants. The isomer pp' DDE was the most frequent substance found in serum and follicular fluid. Serum levels of PCB 138, 153, and 180 were also found in more than $50 \%$ of the samples. The levels of the congener 180 showed a significant difference between patients who achieved pregnancy and those who did not, and pp'DDE presented higher residual levels and was associated with fertilization failure. In the present study, similar results were found, as PCB 180 showed significant difference in the frequency between the groups. However, Buck and cols. (9) found that the values of PCB 206 and HCB were $30 \%$ or more of their detection limits, and those of PCBs 138, 153, and 180 were below the detection limits. Nevertheless, PCB 205 was observed to be the only congener significant and positively associated with increased time to pregnancy.

The association of environmental exposure and adverse effects in human health involves multiple factors. The difficulty in establishing the level of chemical exposure in each geographic region, and the variety of compounds existing simultaneously in the environment, the susceptibility and vulnerability of the host, and the long period of latency between exposure and characterization of the individual responses are well-known (32). Therefore, the limitations of this study, as in many others, include the difficulty in proving causality, especially in an urban area without accidental or chronic population exposure. Although the sample size limited statistical results, it was possible to show increased frequency of organochlorine compounds in the serum of infertile women living in an urban, compared with fertile ones.

\section{CONCLUSIONS}

Women living in a metropolitan area of Rio de Janeiro are exposed to the most prevalent organochlorine compounds described in the literature, even though detection levels are low. The comparison of organochlorine levels in fertile and infertile women indicates that pp'DDE, may adversely influence female fertility.

To achieve more consistency and comparability, future investigations will be essential to better understand how environmental EDs can affect reproductive viability. These studies should involve a large number of samples as well as exclusion criteria for participants similar to those used in other experiments on exposure to organochlorines. 
Acknowledgements: we would like to thank Doctor Ruth Clapauch for the contribution in the discussion of this paper from the endocrinologist standpoint, and for the incentive to publish the article.

Disclosure: no potential conflict of interest relevant to this article was reported.

\section{REFERENCES}

1. Global trends: population growth, but falling birth, fertility rates. Growth Strategies. June, 2001. Find Articles.com. Accessed on: July 26, 2009.

2. Crosignani PG, Rubin BL, Collins HJ. Social determinants of human reproduction. The ESHRE Capri Workshop Group. Hum Reprod. 2001;16(7):1518-26.

3. IBGE - Brazilian Institute of Geography and Statistics. National Research per Home Sampling. (PNAD 2006). Available at: >www. ibge.gov.br< Social Communication, September 28, 2007. Accessed on: Feb 16, 2009.

4. IBGE - Brazilian Institute of Geography and Statistics Prospect of the Brazilian Population by Gender and Age-1980-2050. Revised Edition 2008. Social Communication, November 27, 2008. Available at: <www.ibge.gov.br/presidencia/notícias> Accessed on: Feb 16, 2009.

5. Oliva A, Spira A, Multigner L. Contribution of environmental factors to the risk of male infertility. Hum Reprod. 2001;16(8):1768-76.

6. Greenlee AR, ArbuckleTE, Chyou P. Risk factors for female infertility in an agricultural region. Epidemiology. 2003;14(4):429-36.

7. Yu M, GuoYL, Hsu CC, RoganWJ. Menstruation and reproduction in women with Polychlorinated Biphenyl (PCB) poisoning: longterm follow-up interviews of the women from Taiwan Yucheng cohort. Int J Epidemiol. 2000;29:672-7.

8. Buck GM, Vena JE, Schisterman EF, Dmochowski J, Mendola P, Sever LE, et al. Parental consumption of contaminated sport fish from Lake Ontario and predicted fecundability. Epidemiology. 2000;11(4):388-93.

9. Buck GM, Vena JE, Greizerstein HB, Weiner JM, McGuinness B, Mendola $P$, et al. PCB congeners and pesticides and female fecundity, New York State Angler Prospective Pregnancy Study. Environ Toxicol Pharmac. 2002;12:83-92.

10. Axmon A, Rylander L, Stromberg U, Hagmar L. Time to pregnancy and infertility among women with a high intake of fish contaminated with persistent organochlorine compounds. Scand J Work Environ Health. 2000;26(3):199-206.

11. Axmon A, Rylander L, Stromberg U, Hagmar L. Female fertility in relation to the consumption of fish contaminated with persistent organochlorine compounds. Scand J Work Environ Health. 2002;28:124-32.

12. Colborn T. Endocrine Disruption from Environmental Toxicants. In: Ron WN, ed. Environmental and Occupational Medicine, Philadelphia: Lippincott; 1998. p. 807-1.

13. Stockholm Convention on Persistent Organic Pollutants (POPs): Text of the Convention. Available at: <http://chm.pops.int/Convention/Compliance/DecisionsRecommendations/>. Accessed on: Sept 28, 2007.

14. Colborn T, Clement C. Chemically - induced alterations in sexual and functional development in the wildlike/human connection. Princeton. New Jersey: Princeton Scientific Publishing; 1992.
15. Penteado JCP, Vaz JM. O legado das bifenilas policloradas (PCBs). Quím Nova. 2001;24(3):390-8.

16. Fontenele EGP, Martins MRA, Quidute APP, Montenegro RMJ. Contaminantes ambientais e os interferentes endócrinos. Arq Bras Endocrinol Metab. 2010;54(1):6-16.

17. Uzumcu M, Zachow R. Developmental exposure to environmental endocrine disruptors: consequences within the ovary and on female reproductive function. Reprod Toxicol. 2007;23(3):337-52.

18. DamstraT, Barlow S, Bergman A, Kavlock R, Van Der Kraak G. International Program on Chemical Safety (IPCS) - Global Assessment of the State-of-the-Science of Endocrine Disrupting Chemicals (EDCs). Chapter 5: Human Health; 2002. p. 57-87. Available at: < http://www.ehponline.org/who/ >. Accessed on: Feb, 2007.

19. FosterWG. Environmental toxicants and human fertility. Minerva Ginecol. 2003;55(5):451-5.

20. Baird DD, Weinberg CR, Rowland AS. Reporting erros in time-topregnancy data collected with a short questionnaire. Impact on power and estimation of fecundability ratios. Am J Epidemiol. 1991;133:1282-90

21. Smith EM, Hammonds-Ehlers M, Clark MK, Kirchner HL, Fuortes L. Occupational exposures and risk of female infertility. J Occup Environ Med. 1997;39(2):138-47.

22. Berman T, Levine H, Gamzu R, Grotto I. Trends in reproductive health in Israel: implications for environmental health policy. Isr J Health Policy Res. 2012;1(1):34.

23. Ozen S, Dauan S, Bayindir P, Karasulu E, Sinsek DG, Gürler T. Effects of pesticides used in agriculture on the development of precocious puberty. Environ Monit Assess. 2012;184(7):4223-32.

24. Toshiba H, Suzuki Y, Imai K, Yoshinaga J, Shiraishi H, Mizumoto Y, et al. Endocrine disrupting chemicals in urine of Japanese male partners of subfertile couples: a pilot study on exposure and semen quality. Int J Hyg Environ Health. 2012;215(5):502-6.

25. Caserta D, Mantovani A, Marci R, Fazi A, Ciardo F, La Rocca C, et al. Environment and women's reproductive health. Hum Reprod Update. 2011;17(3):418-33.

26. Silva SA. Contamination for composites organochlorine of the water of distribution of the region metropolitan of Rio de Janeiro: methodology validation. MasterThesis, National School of Public Health, Oswaldo Cruz Foundation, Rio de Janeiro; 2004.

27. Delgado IF, Barretto HHC, Kussumi TA, Alleluia IB, Baggio CA, Paumgartten FJR. Serum levels of organochlorine pesticides and polychlorinated biphenyls among inhabitants of Greater Metropolitan, Rio de Janeiro, Brazil. Cad Saude Publica. 2002;18(2):519-24.

28. Sarcinelli PN, Pereira ACS, Mesquita SA, Silva OJJ, Meyer A, Menezes AAC, et al. Dietary and reproductive determinants of plasma organochlorine levels in pregnant women in Rio de Janeiro. Environ Res. 2003;91:143-50.

29. Longnecker MP, Klebanoff MA, Gladen BC, Berendes HZ. Serial levels of serum organochlorines during pregnancy and postpartum. Arch Environ Health. 1999;54(2):110-4.

30. Safe HS, Hoivik JD. Polychlorinated Biphenyls. Environmental and Occupational Medicine, Chapter 87: 1205-1214. In: Ron WN, ed. 3rd ed. Philadelphia: Lippincott - Raven Publishers; 1998.

31. Younglai EV, Foster WG, Hughes EG, Trim K, Jarrel JF. Levels of environmental contaminants in human follicular fluid, serum and plasma seminal of couples undergoing in vitro fertilization. Arch Environm Contam Toxicol. 2002;43:121-6.

32. WoodruffTJ, Carlson A, Schwartz JM, Giudice LC. Proceedings of the submit of environmental challenges to reproductive health and fertility: executive summary. Fertil Steril. 2008;89(2):281-300. 